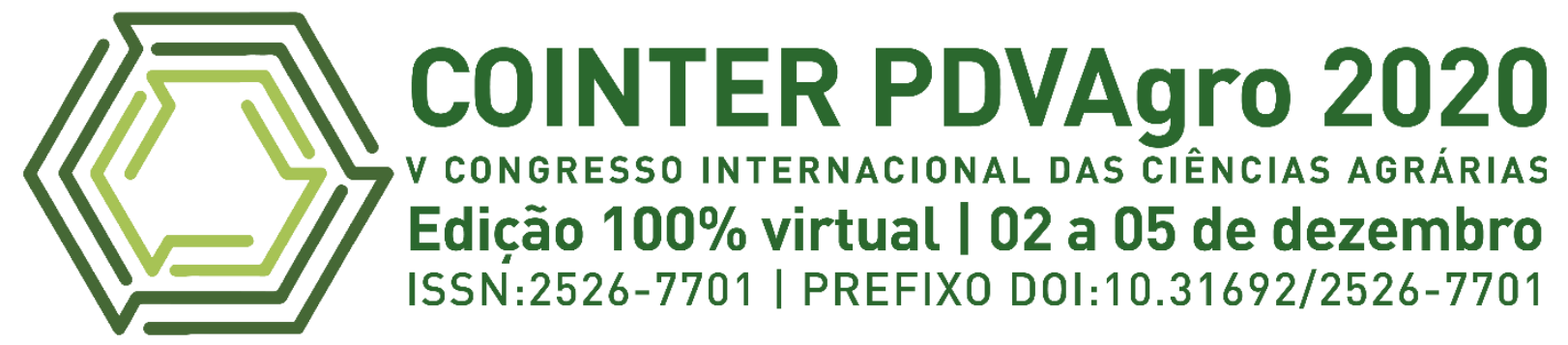

\title{
EVOLUÇÃO DO REBANHO EFETIVO E PRINCIPAIS CARACTERÍSTICAS DA OVINOCAPRINOCULTURA NO ESTADO DO PARÁ
}

\section{EVOLUCIÓN DEL BLOQUE EFECTIVO Y PRINCIPALES CARACTERÍSTICAS DE OVINOCAPRINOCULTURA EN EL ESTADO DE PARÁ}

\section{EVOLUTION OF EFFECTIVE FLOCK AND MAIN CHARACTERISTICS OF OVINOCAPRINOCULTURA IN THE STATE OF PARÁ}

\author{
Apresentação: Comunicação Oral \\ Jefferson Moraes da Silva ${ }^{1}$; Leandro José de Oliveira Míndelo²; Mayse Ferreira Sales ${ }^{3}$; Carlos Alberto de \\ Oliveira Júnior $^{4}$
}

DOI : https://doi.org/10.31692/2526-7701.VCOINTERPDVAgro.0646

\section{RESUMO}

Esta revisão atualiza informações sobre a evolução do rebanho efetivo de ovinos e caprinos no estado do Pará, Brasil, entre os anos de 1974 a 2018, com base nos dados dos Censos Agropecuários publicados pelo Instituto Brasileiro de Geografia e Estatística - IBGE e descreve algumas das principais características das criações desses animais no estado. Atualmente, o rebanho de ovinos e caprinos conta com 156.057 e 95.192 cabeças, respectivamente. As cidades em destaque na produção de ovinos são: Marabá, São Félix do Xingu e Novo Repartimento. E caprinos: Alenquer, Itupiranga e Chaves. O Estado do Pará apresenta um total de 10.445 estabelecimentos que atualmente trabalham com caprinos e ovinos, destes 4.193 criam caprinos e 6.352 criam ovinos. Dos estabelecimentos que produzem caprinos $64,8 \%$ são produtores da agricultura familiar e dos estabelecimentos produtores de ovinos apenas $63 \%$ são da agricultura familiar. O Pará possui atualmente um rebanho de 99.445 mil matrizes e 25.876 reprodutores. Em relação a assistência técnica fornecida apenas 715 estabelecimentos produtores recebem algum tipo de assistência, destes, 226 recebem ajuda do governo e 399 tem assistência própria. No estado do Pará, o sistema de criação predominante de caprinos e ovinos é caracterizado por baixos índices zootécnicos, podemos inferir que este fato é muito influenciado pela falta de estudos e assistência técnica especializada para este tipo de criação, o que leva a uma precária nutrição dos animais, além de problemas sanitários e um manejo ineficiente. Quanto ao perfil socioeconômico dos produtores, observa-se que a maioria se constitui de pequenos proprietários, predominando a utilização de mão de obra familiar e sistema extensivo na criação dos animais.

Palavras-Chave: ovinos, caprinos, ruminantes, pecuária, produção

1 Medicina Veterinária, UFPA, moraesj414@gmail.com

2 Engenharia de Alimentos, IFPA, leandromindelo50@gmail.com

3 Técnico em Agropecuária, IFPA, maysesales07@gmail.com

4 Doutor em Medicina Veterinária, IFPA, carlor.jr@ifpa.edu.br 


\title{
EVOLUÇÃO DO REBANHO EFETIVO E PRINCIPAIS CARACTERÍSTICAS
}

\section{RESUMEN}

Esta revisión actualiza información sobre la evolución del rebaño efectivo de ovejas y cabras en el estado de Pará, Brasil, de 1974 a 2018, con base en datos del Censo Agropecuario publicado por el Instituto Brasileño de Geografía y Estadística - IBGE y describe algunas de las Principales características de las creaciones de estos animales en el estado. Actualmente, el rebaño de ovinos y caprinos tiene $156.057 \mathrm{y}$ 95.192 cabezas, respectivamente. Las ciudades destacadas en la producción ovina son: Marabá, São Félix do Xingu y Novo Repartimento. Y cabras: Alenquer, Itupiranga y Chaves. El Estado de Pará cuenta con un total de 10.445 establecimientos que actualmente trabajan con cabras y ovejas, de los cuales 4.193 crían cabras y 6.352 crían ovejas. De los establecimientos que producen cabras el 64,8\% son productores de agricultura familiar y de los establecimientos que producen ovinos solo el $63 \%$ son de agricultura familiar, Ṕará cuenta actualmente con un rebaño de 99.445 mil cerdas y 25.876 ganaderos. En cuanto a la asistencia técnica brindada, solo 715 establecimientos productores reciben algún tipo de asistencia, de estos, 226 reciben asistencia gubernamental y 399 cuentan con asistencia propia. En el estado de Pará, el sistema de crianza predominante para cabras y ovinos se caracteriza por índices zootécnicos bajos, podemos inferir que este hecho está muy influenciado por la falta de estudios y asistencia técnica especializada para este tipo de cría, lo que conduce a una mala nutrición. animales, así como problemas de salud y manejo ineficiente. En cuanto al perfil socioeconómico de los productores, se observa que la mayoría está conformada por pequeños propietarios, con predominio del uso de mano de obra familiar y un sistema extensivo en la crianza de los animales.

Palabras-Clave: ovino, caprino, rumiante, ganadería, producción

\begin{abstract}
This review updates information on the evolution of the effective herd of sheep and goats in the state of Pará, Brazil, from 1974 to 2018, based on data from the Census of Agriculture published by the Brazilian Institute of Geography and Statistics - IBGE and describes some of the main characteristics of the creations of these animals in the state. Currently, the flock of sheep and goats has 156,057 and 95,192 heads, respectively. The cities highlighted in sheep production are: Marabá, São Félix do Xingu and Novo Repartimento. And goats: Alenquer, Itupiranga and Chaves. The State of Pará has a total of 10,445 establishments that currently work with goats and sheep, of which 4,193 breed goats and 6,352 breed sheep. Of the establishments that produce goats $64.8 \%$ are producers of family agriculture and of the establishments that produce sheep only $63 \%$ are of family agriculture. Ṕará currently has a herd of 99,445 thousand sows and 25,876 breeders. Regarding the technical assistance provided, only 715 producing establishments receive some type of assistance, of these, 226 receive government assistance and 399 have their own assistance. In the state of Pará, the predominant breeding system for goats and sheep is characterized by low zootechnical indexes, we can infer that this fact is greatly influenced by the lack of studies and specialized technical assistance for this type of breeding, which leads to poor nutrition animals, as well as health problems and inefficient handling. As for the socioeconomic profile of the producers, it is observed that the majority is made up of smallholders, with the predominance of the use of family labor and an extensive system in raising the animals.
\end{abstract}

Keywords: sheep, goats, ruminants, livestock, production

\section{INTRODUÇÃO}

O Brasil possui atualmente um rebanho de aproximadamente 13.789 .345 milhões de ovinos e 8.260.607 milhões de caprinos, distribuídos nas diferentes regiões do país, sendo que a região nordeste possui maior rebanho, seguida da região sul do Brasil (IBGE, 2017). Na região norte, a prática da criação de ovinos e caprinos é praticada por um pequeno grupo de criadores quando comparado a outras regiões do Brasil. Em propriedades rurais de baixo nível 
tecnológico. No estado do Pará o efetivo total de caprinos é de 95.112 cabeças e 156.057 de ovinos, o número de estabelecimentos atual é de 6.377 para ovinos e 4.220 para caprinos.

A criação de cabras está ligada ao ser humano desde o princípio da civilização e foi importante para auxiliar no surgimento de assentamentos fixos, fornecendo carne, pele e leite. Nos tempos atuais a criação de caprinos ainda visa obter esses três tipos de insumos. (SAMPAIO et al., 2009)

A ovinocaprinocultura se define pela criação de ovinos e caprinos nos diferentes tipos de sistema como: sistema extensivo, semi-intensivo e intensivo. Com isso o produtor precisa principalmente utilizar de estratégias, no sentido de promover o desenvolvimento dos animais em algumas regiões principalmente, quando se leva em consideração a escolha de raças adaptadas a determinado ambiente exposto a elas. A atividade ainda se destaca pela característica de ser de subsistência, ou seja, para o consumo familiar o que delimita as criações em alguns estados brasileiros (EMBRAPA, 2005).

A criação de ovinos e caprinos é de grande importância socioeconômica para proprietários de pequenas áreas podendo suprir a carência de proteína animal, pois produzem carne e leite de excelente sabor e qualidade, além de proporcionar outras vantagens como: baixo investimento na aquisição dos animais; baixo investimento em instalações, (AZEVEDO et. al. 1998) Porém não obtivemos uma evolução significativa em relação ao que foi citado por Souza Neto, 1986 que diz que poucas informações estão disponíveis sobre a criação desses animais na Amazônia. Depois de 34 anos infelizmente ainda temos poucas informações precisas sobre a criação de ovinos e caprinos na região norte do país.

Porém, o mercado de ovinocaprinocultura vem ganhando espaço no setor agropecuário brasileiro e importância na economia, como uma alternativa rentável aos produtores. Os principais produtos comercializados desse setor são: carne, pele, lã, leite e produção de queijos a partir do leite. (SEBRAE, 2017)

Nas últimas duas décadas, incentivos e recursos das instituições públicas têm sido disponibilizados com o intuito de consolidar as cadeias agroindustriais da caprinocultura e da ovinocultura como alternativas de alimentos de origem animal e de enfrentamento dos diversos desafios verificados pelo setor. Como resultado dessas ações, esses setores têm apresentado algumas mudanças pontuais de sucesso. Entretanto, devido a motivos diversos, tais mudanças não têm causado o impacto necessário para transformar essas atividades em um negócio estruturado e lucrativo, como é esperado por todos os integrantes dessas cadeias produtivas. (QUADROS E CRUZ, 2017). 


\section{EVOLUÇÃO DO REBANHO EFETIVO E PRINCIPAIS CARACTERÍSTICAS}

A Caprinocultura é um ramo com grande potencial a ser explorado, porém não muito reconhecido, especializado e incentivado por ações governamentais como ocorre com outros tipos de cultura. (NASCIMENTO et.al., 2015)

Portanto, a importância econômica do setor para a agropecuária brasileira traz um crescente interesse no acompanhamento dos seus resultados, pela análise do comportamento dos indicadores, cenários e perspectivas. A análise de resultados anteriores é fundamental para o entendimento da conjuntura e previsão de tendências, o que leva em consideração diversos fatores estruturais e de mercado. Dentre as principais fontes de informações da agropecuária, o Censo Agropecuário realizado pelo Instituto Brasileiro de Geografia e Estatística - IBGE se destaca e representa a maior base de informações para o setor de forma sistematizada. (MAGALHÃES, et. al. 2018)

As tendências para o mercado ovinos e caprinos são promissoras, conforme FAO (2007), a demanda de carne nos países em desenvolvimento vem sendo impulsionada pelo crescimento demográfico, pela urbanização e pelas variações das preferências e dos hábitos alimentares dos consumidores. Dessa forma, estima-se um crescimento anual de $2,1 \%$ na produção de carne ovinacaprina, registrando-se essa elevação principalmente em países em desenvolvimento. Fatores como a diversidade étnica e a valorização de produtos cárneos desossados fortalecerão o comércio de carne no período de projeção. Também se espera o aumento da demanda de importações pelos países da América do Norte, Europa e Oriente Médio, o que beneficiará principalmente as exportações procedentes da Oceania.

O Brasil pode-se beneficiar do aumento da demanda de carne ovina pelos países importadores. $\mathrm{O}$ aumento do rebanho nacional, o incremento da oferta de animais jovens para abate e o fortalecimento da cadeia produtiva através da organização de produtores são desafios a serem alcançados para que o país possa exportar a carne ovina para paises de maior consumo. (VIANA, 2008)

O agronegócio da caprinocultura e da ovinocultura de corte está expandindo-se rapidamente por todas as regiões do País, permitindo sua projeção no cenário nacional como atividade de relevante importância socioeconômica. As crescentes demandas dos mercados interno e externo para os produtos derivados dos caprinos e ovinos têm chamado a atenção de técnicos e produtores, impondo a busca por novos conhecimentos. (EMBRAPA, 2005) Essa é uma oportunidade de trabalho real para novos técnicos desenvolverem essas atividades de forma a apresentar viabilidade econômica. A ovinocultura e a caprinocultura são criações bem atrativas, principalmente para áreas de terra relativamente pequenas, pois apresentam alta capacidade de produção. (QUADROS, 2018) 
No longo prazo, o aumento na produção e consumo dos produtos dessas cadeias é algo que deve ocorrer em função de alguns fatores, seja pelo crescimento natural da população e da renda, seja pela organização desses setores que consiga expandir seu mercado, dado o seu potencial.

É preciso enfatizar, todavia, que a organização e a gestão da unidade produtiva sejam trabalhadas como ferramentas fundamentais para o sucesso de qualquer empreendimento. Fortalecer esses conceitos perante os produtores é crucial para a inserção da produção de âmbito familiar no agronegócio e, de maneira geral, para a consolidação dessas atividades, tendo como foco os mercados localizados além das fronteiras regionais. O domínio das mais importantes práticas de manejo em cada fase de produção, aliado aos conhecimentos sobre recursos genéticos, alimentação e sanidade, são estratégias relevantes para garantir a otimização dos recursos disponíveis e o incremento econômico, valorizando cada vez mais os produtos obtidos. Naturalmente, que as boas práticas incluem o processamento dos produtos da caprinocultura e ovinocultura, o qual projeta-se como alternativa para a agregação de valor e a conquista de novos mercados. Por conseguinte, o conhecimento de tópicos técnicos e organizacionais da produção deve também estar associado aos aspectos que constituem o mercado, o processamento e a comercialização dos derivados obtidos na atividade.

Muitos conceitos básicos são ainda desconhecidos dos produtores tradicionais de caprinos e ovinos, limitando a viabilidade da atividade e sua consolidação como parte integrante do agronegócio. (EMBRAPA, 2005)

No entanto, questões culturais precisam ser superadas, ao mesmo tempo em que os aspectos organizacionais precisam ser equacionados, e nesses aspectos desponta fortemente a questão da formalização do abate e da inspeção sanitária dos produtos.

Assim como em outras cadeias, isso não deverá ocorrer por força de lei, mas sim pela percepção de que a organização do setor permite maiores ganhos, atraindo investidores de maior porte. Por outro lado, o pequeno produtor, inclusive familiar, deve ser colocado como elemento essencial no direcionamento estratégico, dada sua importância produtiva e social. Isso também está relacionado ao aspecto dicotômico das duas cadeias, dado que os principais mercados desses produtos têm duas frentes bem definidas, de um lado o consumo de caráter regional e tradicional, associado a produtos mais simples e de baixo valor agregado, e de outro, o consumo gourmet, em centros urbanos com maior renda média.(QUADROS,2018)

O mercado brasileiro é altamente consumidor de carnes caprinas e ovinas, tendo em vista o volume de importação que vem ocorrendo todos os anos. Nesse sentido, a união de esforços poderá ampliar a capacidade dos produtores brasileiros em atender à demanda interna 
e preencher uma lacuna de mercado que já existe há algum tempo (MARTINS; MAGALHÃES; SOUZA, 2016).

Dessa forma o objetivo deste trabalho é avaliar informações sobre a evolução do rebanho efetivo de ovinos e caprinos no estado do Pará, Brasil, entre os anos de 1974 a 2018, a partir de dados dos censos agropecuários publicados pelo Instituto Brasileiro de Geografia e Estatística - IBGE.

\section{REVISÃO BIBLIOGRÁFICA}

\section{EVOLUÇÃO DO REBANHO OVINO}

Atualmente no Pará, segundo IBGE (2017), quatro cidades se destacam na produção de ovinos, são elas: Marabá, São Félix do Xingu e Novo Repartimento.

Ao analisar os dados disponíveis pelo IBGE, especialmente em relação a criação de ovinos, correspondentes aos anos de 1974 a 2018 pode-se constatar que, no que tange este setor obteve-se crescimento significativo no número de cabeças. Entretanto, mesmo aumentando em mais de $400 \%$ seu quantitativo de ovinos, o estado ainda não se configura como importante dentro do mercado produtor e consumidor do País, o gráfico abaixo traz em números o crescimento do rebanho caprino estadual.

Figura 1: Número de ovinos (cabeças) do Estado do Pará durante os anos de 1974 a 2018

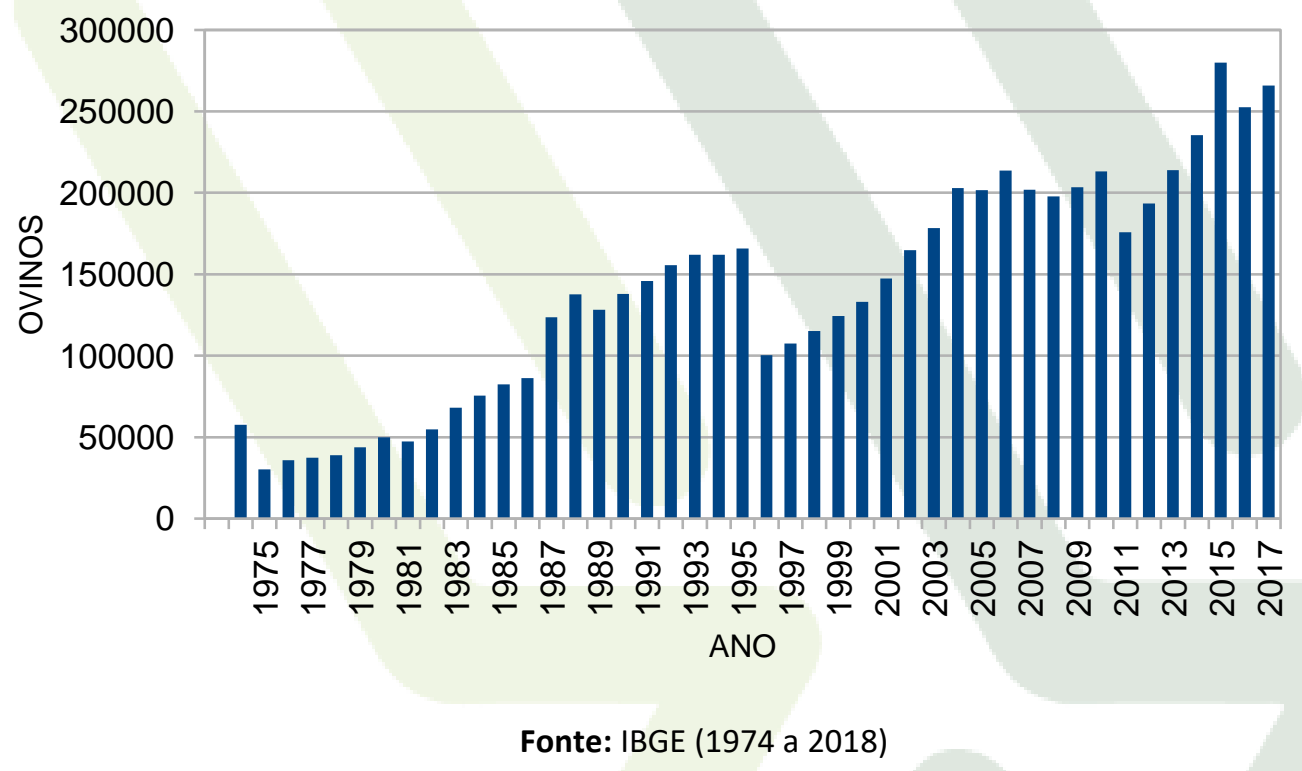

O Pará de acordo com Embrapa (2018), vai na contramão do cenário nacional, visto que, ao analisar especificamente a ovinocultura e caprinocultura, observa-se uma redução no rebanho ovino nacional e um crescimento do rebanho caprino, com um aumento da concentração regional em ambas as espécies. 
Embrapa (2018) ressalta ainda que apesar do número reduzido de cabeças da região, o Norte apresenta os maiores preços médios iniciais de comercialização de carne. Concordando com FAO (2007), que cita sobre a estimativa de crescimento da demanda de carne ovina.

No Pará três municípios apresentaram percentuais de crescimento bastante animadores na ovinocultura em dados analisados durante os anos de 2013 a 2018. O município de Benevides apresentou crescimento percentual de 916,6\%, Porto de Moz foi outro município paraense que se destacou durante esse período com um crescimento percentual de 1129,4\% e Santa Izabel do Pará assim como os demais citados acima também apresentou um crescimento significativo no números de animais, obtendo crescimento de $770 \%$ em seu rebanho, passando de 70 animais em 2013 para 609 em 2018.

Figura 2: Crescimento no número de Ovinos (cabeças) por município durante os anos de 2013 a 2018

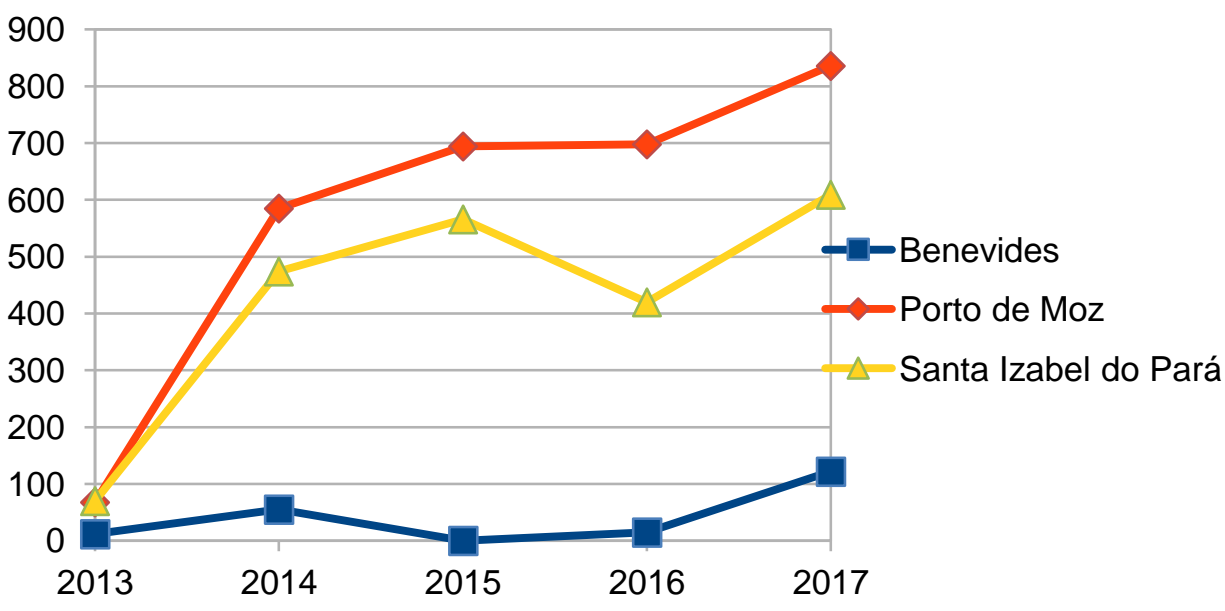

Fonte: IBGE (2013 a 2018)

Assim como pode-se identificar os três munícipios que apresentaram o melhor saldo positivo nos últimos anos, três cidades do estado também se destacaram, porém de forma negativa em relação a criação de ovinos. A cidade de Bujaru apresentou redução significativa no seu rebanho total representada por uma queda de $1900 \%$ no rebanho total do município. $\mathrm{Na}$ mesma perspectiva, Santo Antônio do Tauá foi outra cidade do Estado que apresentou grande queda em seu efetivo de ovinos, uma queda que apresenta em escala real 1026\% na produção municipal. Por fim, São Francisco do Pará assemelha-se em números a Santo Antônio do Tauá apresentando regressão de $1050 \%$, passando de 575 para 50 cabeças. 


\section{EVOLUÇÃO DO REBANHO EFETIVO E PRINCIPAIS CARACTERÍSTICAS}

Figura 3: Queda no número de Ovinos (cabeças) por município durante os anos de 2013 a 2018

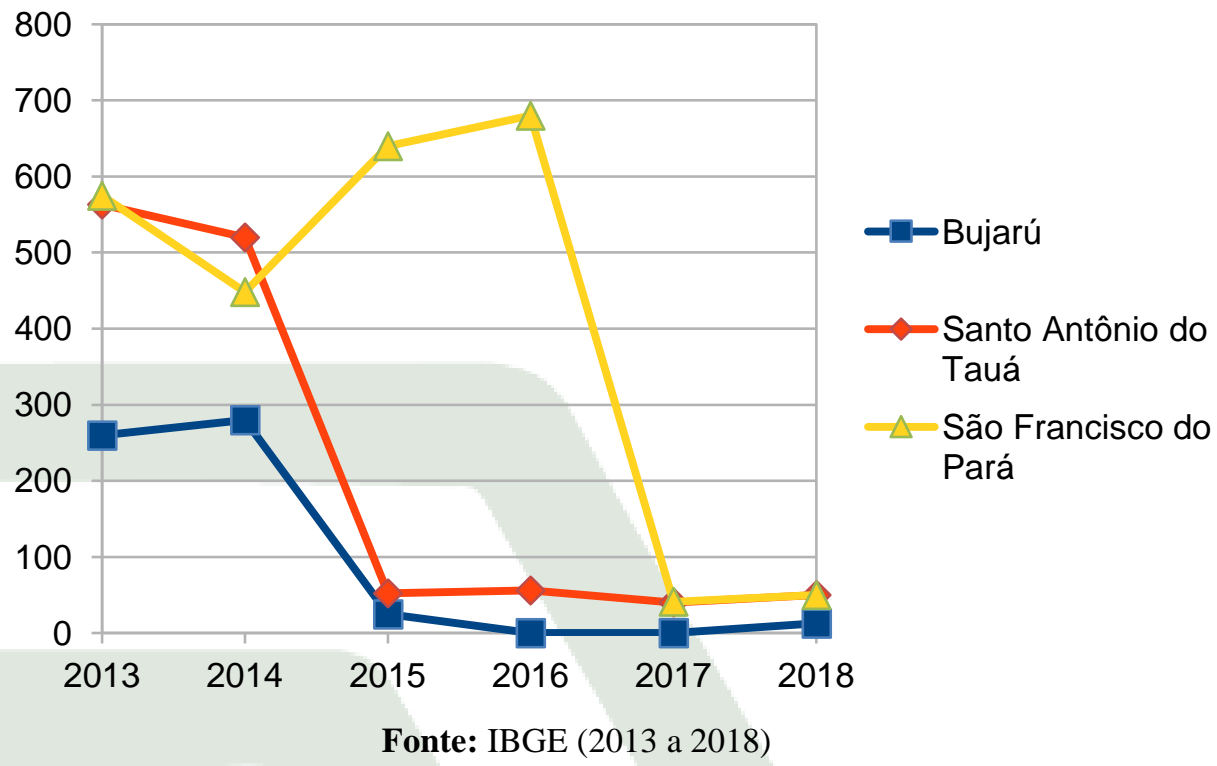

\section{EVOLUÇÃO DO REBANHO CAPRINO}

Partindo-se da análise dos dados publicados pelo IBGE, referentes ao censo agropecuário 2017, constatou-se que o efetivo de rebanho caprino paraense sofreu uma redução de 1,69\% comparando aos dados dos anos 2017 e 2018, passando de um efetivo total de 83.234 mil cabeças para 81.824 mil cabeças.

Em relação a produção de caprinos, o gráfico abaixo demonstra que o estado sofreu grandes perdas no número de animais, entre os anos de 1974 a 1995, os números mostram uma grande expansão de produção, porém, a partir de 1995 em contramão ao reflexo nacional de crescimento da cadeia produtiva da ovinocultura que passou a apresentar acentuação relevante, a cadeia produtiva de caprinos decresceu bastante. Para fins de comparação no ano de 1995, ano esse que apresentou maior número de animais, obtivemos um total de 178.523 cabeças, porém no dado mais recente divulgado pelo IBGE obtivemos apenas 81.224 cabeças, uma queda brusca que chega a corresponder $119 \%$ no total. 
Figura 4: Número de caprinos (cabeças) do Estado do Pará durante os anos de 1974 a 2018

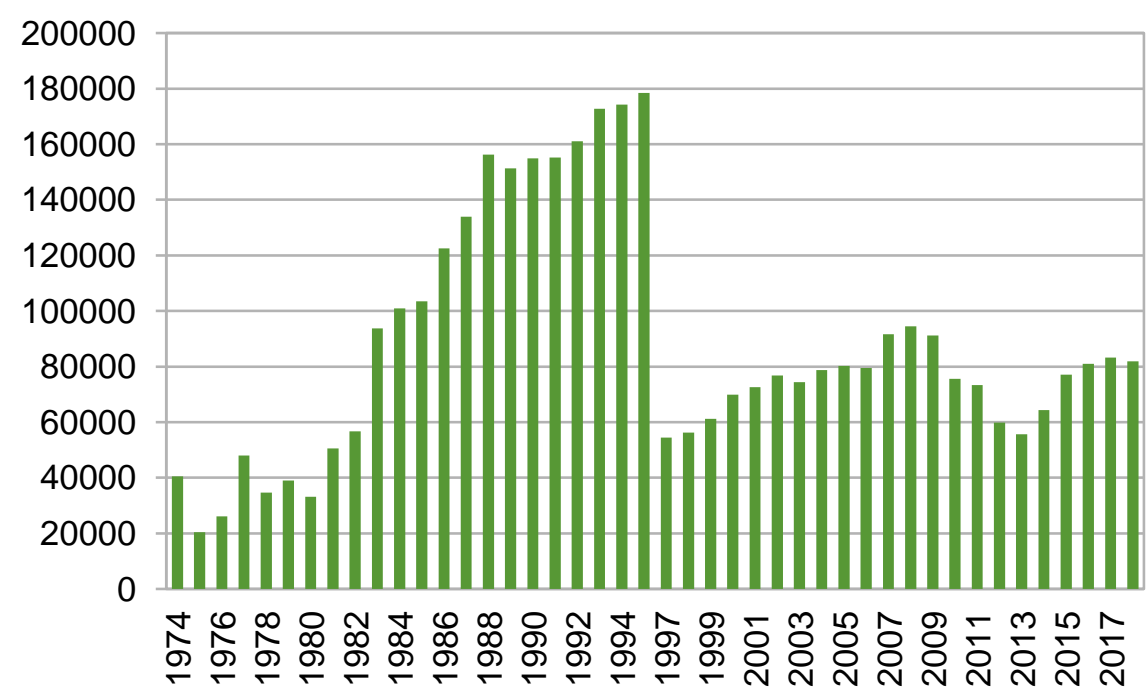

Fonte: IBGE (1974 a 2018)

Fazendo referência a cadeia produtiva da Caprinocultura, três cidades apresentaram crescimento positivos, cita-se aqui neste artigo a cidade de Almeirim que, apesar de apresentar pouca produção comparada a outros municípios do estados vem apresentando grande crescimento do seu rebanho caprino, no ano de 2006, foram catalogadas apenas 20 animais na região, porém, a cidade vem apresentando anualmente resultados positivos chegando a configurar 943 animais no ano de 2018, uma alta de 4615\% nos últimos cinco anos.

Ananindeua apesar de ser uma cidade da região metropolitana do Estado aos poucos vem se estabelecendo na cadeia produtiva da caprinocultura, o município vem apresentando altas sucessivas no número de animais, no ano de 2006 Ananindeua apresentava apenas 5 animais, a alta foi tanta que chega a alcançar $3400 \%$, atualmente a cidade tem em seu rebanho um total de 184 animais. Complementando estas cidades, Trairão é o município que mais se destaca na criação de pequenos ruminantes, o rebanho de caprinos atual é de 9450 animais, o mesmo apresentou um crescimento de $3262,9 \%$ nos últimos 5 anos, visto que, o número de animais no ano de 2006 era de 281 cabeças. 


\section{EVOLUÇÃO DO REBANHO EFETIVO E PRINCIPAIS CARACTERÍSTICAS}

Figura 5: Crescimento no número de Caprinos (cabeças) por município durante os anos de 2013 a 2018

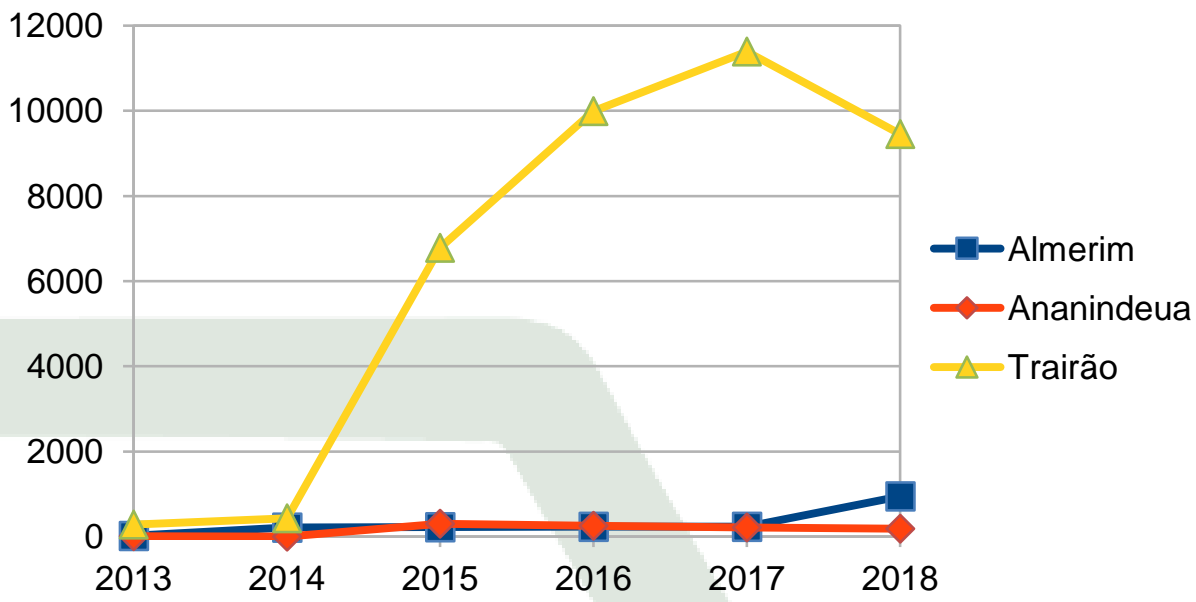

Fonte: IBGE (2013 a 2018)

Já em relação aos municípios que apresentaram regressão no número de animais destacam-se: Brejo Grande do Araguaia, Conceição do Araguaia e Viseu. A primeira, por mais que não tenha em nenhum momento se destacado na produção caprina estadual, o número de animais no município vem apresentando seguidas quedas nos últimos anos, em 2006 o município apresentava 160 cabeças caprinas, porém, ao longo de cinco anos apresentou queda percentual de 966,6\% passando para um total de apenas 15 animais. O município de Conceição do Araguaia foi apresenta inúmeras quedas no seu rebanho total, totalizando uma regressão de aproximadamente 280,5\%. Já a cidade de Viseu, passou de um número total de 1876 animais em 2006 para 442 em 2018, uma queda que representa 324,4\% no rebanho municipal.

Figura 6: Queda no número de Caprinos (cabeças) por município durante os anos de 2013 a 2018

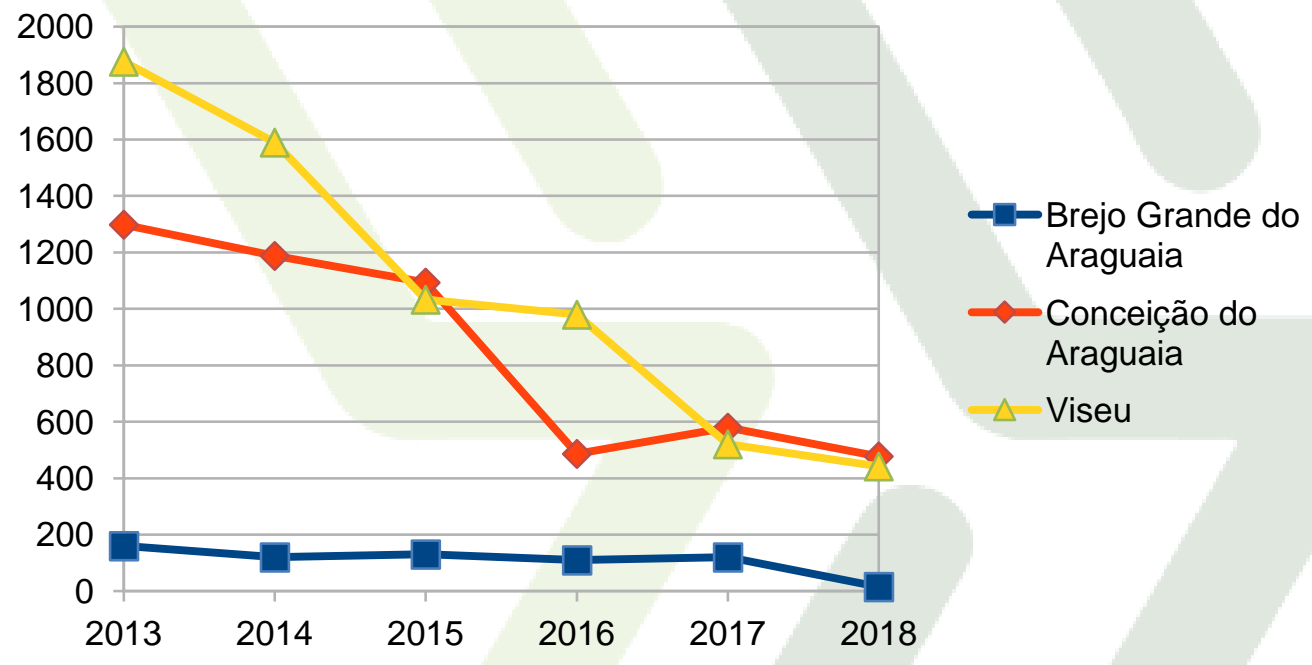

Fonte: IBGE (2013 a 2018) 


\section{CARACTERÍSTICAS REGIONAIS DA PRODUÇÃO DE CAPRINOS E OVINOS}

Segundo dados do IBGE do ano de 2017, o Estado do Pará apresenta um total de 10.445 estabelecimentos que atualmente trabalham com caprinos e ovinos, destes 4.193 criam caprinos e 6.352 criam ovinos. Segundo Embrapa (2018), em termos de número de estabelecimentos no país, para caprinos houve um crescimento de 16,5\% entre os Censos Agropecuários de 2006 e 2017, enquanto para ovinos o crescimento foi de $20,0 \%$.

A o analisarmos os dados estatisticamente podemos observar que o Estado representa apenas $1,28 \%$ da produção de caprinos nacional e 1,24\% da produção de ovinos.

Dos estabelecimentos que produzem caprinos 64,8\% são produtores da agricultura familiar e dos estabelecimentos produtores de ovinos apenas $63 \%$ são da agricultura familiar.

Porém, ao analisarmos os dados dos estabelecimentos levando em consideração a quantidade de cabeças por propriedade podemos observar que a grande maioria são de tamanho pequenas ou médias, cerca de $80 \%$ das propriedades não alcança 100 cabeças de animais.

O Pará possui atualmente um rebanho de 99.445 mil matrizes e 25.876 reprodutores. Em relação a assistência técnica fornecida apenas 715 estabelecimentos produtores recebem algum tipo de assistência, destes, 226 recebem ajuda do governo e 399 tem assistência própria.

No estado do Pará, o sistema de criação predominante de caprinos e ovinos é caracterizado por baixos índices zootécnicos, podemos inferir que este fato é muito influenciado pela falta de estudos e assistência técnica especializada para este tipo de criação, o que leva a uma precária nutrição dos animais, além de problemas sanitários e um manejo ineficiente. Há necessidade do desenvolvimento de ações que possam difundir a importância desses animais na pequena propriedade, bem como priorizá-los em programas de incentivos. (AZEVEDO et. al. 1998)

Quanto ao perfil socioeconômico dos produtores, observa-se que a maioria se constitui de pequenos proprietários, predominando a utilização de mão de obra familiar e sistema extensivo na criação dos animais. Concordando com Quadros e Cruz (2017), onde os autores citam que a administração das propriedades ainda é pouco profissional, com falta de assistência técnica e de extensão rural para produção e gerenciamento, apesar da rápida expansão da ovinocaprinocultura de corte, urge o fortalecimento de vários setores da cadeia produtiva

\section{CONCLUSÕES}

O Estado do Pará apresenta grande potencial de expansão da ovinocaprinocultura, os dados analisados apresentam resultados animadores, visto que, a queda do número de cabeças de caprinos e suprida pelo aumento do número de cabeças de ovinos. Por outro lado, a falta 
de demanda do mercado consumidor faz com que proprietários não almejem o crescimento do rebanho, optando por criar apenas uma pequena quantidade de animais, somente para consumo próprio.

Dessa forma, alguns municípios da região sudeste do Estado tem se destacado na produção, como é o caso do município de Trairão e de Marabá, porém, a falta de investimentos em políticas públicas voltadas para o setor também impede sua Ascenção, uma vez que faltam incentivos para as cadeias produtivas no Estado. Portanto, tal fato se dá por motivos culturais, o Estado não tende a consumir carne caprina e ovina em grande quantidade, o consumo de carne caprina por habitante no Brasil não chega a $1 \mathrm{~kg} / \mathrm{ano}$.

\section{REFERÊNCIAS}

AZEVEDO, G.P.C. de; RODRIGUES FILHO, J.A.; CARVALHO, R. de A.; SARMENTO, C.M.B.; GONÇALVES, C.A. Características dos sistemas de produção de ovinos e caprinos do nordeste paraense. Belém: Embrapa-CPATU, 1998.

EMBRAPA. Caprinos e ovinos de corte - coleção 500 perguntas 500 respostas, 2005.

EMBRAPA. Análise de conjuntura do mercado de caprinos e ovinos: sinais, tendências e desafios, Sobral/CE, 2018.

FAO. Organização das Nações Unidas para a Agricultura e Alimentação. Estatísticas FAO, 2007.

GARCIA, C. A. Ovinocultura e Caprinocultura. Marília: Universidade de Marília, 2004. 22 f. Apostila.

IBGE - INSTITUTO BRASILEIRO DE GEOGRAFIA E ESTATÍSTICA. Censo Agropecuário. 1994 a 2018.

MAGALHÃES, K.A.; FILHO, Z.F.M.; LUCENA, Z.F.A; MARTINS, E.C.; Análise da conjuntura do mercado de caprinos: sinais, tendências e desafios, 2018.

MARTINS, E.C.;Análise da conjuntura do mercado de caprinos e ovinos: sinais, tendências e desafios, 2018.

MARTINS, E. C.; MAGALHÃES, K. A.; SOUZA, J. D. F. Cenários mundial e nacional da caprinocultura e da ovinocultura. Boletim Ativos de Ovinos e Caprinos, 2016.

NASCIMENTO, V.S.O.; LIMA, E.S; PINHEIRO, G.O.; SOUZA, U.A.F; Caprinocultura: Desenvolvimento e desafios, 2015.

NOGUEIRA FILHO, A. sistema Agroindustrial e Potencialidades da Ovinocaprinocultura. Disponível em: <http://www.ovinocultura.com.br> Acesso em 20 mar. 2020.

QUADROS, D.G. ; CRUZ, J.F.; Produção de ovinos e caprinos de corte. - Salvador: EDUNEB, 2017.

QUADROS, D. G. ; Cadeia produtiva da ovinocultura e da caprinocultura. - Indaial: UNIASSELVI, 2018.

SAMPAIO, B. \& SAMPAIO, Y. \& LIMA, R. et al. Perspectivas para a caprinocultura no Brasil: O caso de Pernambuco. 2009.

SANTOS, W. B.; AHID, S. M. M.; SUASSUNA, A. C. D. 2006. Aspectos epidemiológicos da caprinocultura e ovinocultura no município de Mossoró (RN). A Hora Veterinária. v. 26, n.152, p. 25-28.

SEBRAE; Agronegócios: Caprinocultura leiteira, 2017

SIMPLÍCIO, A. A. A caprino-ovinocultura na visão do agronegócio. Revista Conselho Federal de Medicina Veterinária. Brasília/DF, n. 24, ano VII, p. 15-18, set/out/dez 2001. 
SORIO, A. 2017 - Engenheiro Agrônomo. Diagnóstico da oferta e demanda de ovinos e caprinos para processamento de carne, pele e leite na região central do Tocantins, pg. 3,4, 15-25, 83-90.

SOUZA NETO, J. de. Demanda potencial de carne de caprinos e ovinos e perspectivas de oferta, 1985/1990. Sobral: Embrapa-CNPC, 1986. 16p. (Embrapa-CNPC.Documentos, 2).

VIANA, J.G.A.; Panorama geral da ovinocultura no mundo e no Brasil. Revista Ovinos, 2008.

VILLARROEL, A. B. S.; LIMA, L. E. S.; OLIVEIRA, S. M. P. de; FERNANDES, A. A. O. 2006 - Ganho de peso e rendimento de carcaça de cordeiros mestiços Texel e Santa Inês $x$ SRD em sistema de manejo semi intensivo. Ciência e Agrotecnologia, São Paulo, v. 30, n. 5, p. 971-976.

VILLELA, L.C.V., 2016. Ovinos de corte. Disponível em: https://www.agencia.cnptia.embrapa.br/gestor/ovinos_de_corte/arvore/CONT000g8k752f602 wx5ok0u5nfpmb11ubx5.html. Acesso dia 22 de junho de 2020. 